\title{
Publisher Correction: Triparental plants provide direct evidence for polyspermy induced polyploidy
}

\author{
Thomas Nakel ${ }^{1}$, Dawit G. Tekleyohans (1) ${ }^{1}$, Yanbo Mao ${ }^{1}$, Golo Fuchert ${ }^{2}$, Dieu Vo ${ }^{1} \&$ Rita Groß-Hardt ${ }^{1}$
}

Correction to: Nature Communications https://doi.org/10.1038/s41467-017-01044-y; published online 18 October 2017.

This Article contained errors in Fig. 3 that were brought to our attention by the authors during the production process but, inadvertently, were not corrected before publication. The tick marks on the $y$-axis in panels $\mathrm{b}, \mathrm{f}$, and $\mathrm{k}$, and the median line in the boxand-whisker plot for biparental diploid plants (BP) in panel i were shifted downwards by up to 2 mm. This has now been corrected in both the PDF and HTML versions of the Article.

Published online: 11 April 2018

(c) Open Access This article is licensed under a Creative Commons Attribution 4.0 International License, which permits use, sharing, adaptation, distribution and reproduction in any medium or format, as long as you give appropriate credit to the original author(s) and the source, provide a link to the Creative Commons license, and indicate if changes were made. The images or other third party material in this article are included in the article's Creative Commons license, unless indicated otherwise in a credit line to the material. If material is not included in the article's Creative Commons license and your intended use is not permitted by statutory regulation or exceeds the permitted use, you will need to obtain permission directly from the copyright holder. To view a copy of this license, visit http://creativecommons.org/licenses/by/4.0/.

(C) The Author(s) 2018

\footnotetext{
${ }^{1}$ University of Bremen, Centre for Biomolecular Interactions, Leobener Straße 5, 28359 Bremen, Germany. ${ }^{2}$ Max-Planck-Institute for Plasma Physics, Wendelsteinstraße 1, 17491 Greifswald, Germany. Thomas Nakel and Dawit G. Tekleyohans contributed equally to this work. Correspondence and requests for materials should be addressed to R.GB-H. (email: gross-hardt@uni-bremen.de)
} 